\title{
Oral Health-Related Quality of Life of Saudi Young Adults with Vertical Discrepancies in Occlusion
}

This article was published in the following Dove Press journal:

Patient Preference and Adherence

\author{
Nour H Altouki' \\ Maryam A Albrahim ${ }^{2}$ \\ Ali $\mathrm{H} \mathrm{Hassan}^{3}$ \\ Zuhair S Natto ${ }^{4}$ \\ Manar K Alhajrasi ${ }^{5}$ \\ 'Saudi Board of Orthodontics, Jeddah \\ Specialty Dental Center, MOH, Jeddah, \\ Saudi Arabia; ${ }^{2}$ Faculty of Dentistry, King \\ Abdulaziz University, Jeddah, Saudi \\ Arabia; ${ }^{3}$ Department of Orthodontics, \\ Faculty of Dentistry, King Abdulaziz \\ University, Jeddah, Saudi Arabia; \\ ${ }^{4}$ Department of Dental Public Health, \\ Faculty of Dentistry, King Abdulaziz \\ University, Jeddah, Saudi Arabia; ${ }^{5}$ Jeddah \\ Specialty Dental Center, Ministry of \\ Health, Jeddah, Saudi Arabia
}

Background: Malocclusion is one of the most common oral health problems that affects quality of life. It is important to understand how different types of malocclusion can affect the oral health-related quality of life (OHRQoL). Vertical discrepancy in occlusion is highly prevalent, yet there are no studies evaluating its impact on OHRQoL in the Saudi population. Therefore, in this study, we aim to investigate the impact of vertical discrepancy in occlusion on patients' OHRQoL.

Patient and Methods: A cross-sectional evaluation of 109 patients with open and deep bites who attended the orthodontics screening clinic at King Abdulaziz University Dental Hospital was carried out. The OHRQoL of each participant was assessed using the shortened, Arabic-version of the oral health impact profile-14 questionnaire. Chi-squared and Fisher's exact tests were used for analysis.

Results: The findings indicated a statistically significant association between anterior vertical discrepancy in occlusion and embarrassment $(p=0.001)$, followed by being selfconscious about their appearance, discomfort while eating $(p=0.009)$, generalized mouth aching $(p=0.012)$, and speech problems $(p=0.049)$. This Impact was significantly higher in participants with open bites. Regarding gender variables, female patients were found to be significantly more embarrassed $(p=0.005)$, while male patients were more self-conscious $(p=0.018)$.

Conclusion: Vertical discrepancy in occlusion has a negative impact on OHRQoL and its domains in both genders. The negative impact is highlighted in the psychological disability, psychological discomfort, physical pain, and functional limitation domains.

Keywords: malocclusion, OHIP-14, OHRQoL, open bite, deep bite

\section{Introduction}

Oral health-related quality of life (OHRQoL) is defined as

A multidimensional construct that reflects (among other things) people's comfort when eating, sleeping, and engaging in social interaction; their self-esteem; and their satisfaction with respect to their oral health. ${ }^{1}$

OHRQoL is a growing vital concept in dentistry as its understanding enriches three areas: research, clinical practice, and education. ${ }^{2}$ It is an important tool for the dentist as it translates the subjective perceived impact of a certain oral health problem, ${ }^{3}$ while reminding them that they are treating a human being, and not only an oral health problem, such as malocclusion. ${ }^{4}$ OHRQoL should be considered a part of the patient's diagnosis as it helps maximizing the benefits for them. ${ }^{5}$
Correspondence: Ali H Hassan Department of Orthodontics, Faculty of Dentistry, King Abdulaziz University, PO Box 80209, Jeddah 21589, Kingdom of Saudi Arabia

Tel +966503647336

Email aakbr@kau.edu.sa 
Patient's quality of life can be affected by oral health status, presence of a disease such as rheumatoid arthritis and malocclusion. ${ }^{6}$

Malocclusion is one of the most common oral health problems that affects quality of life. ${ }^{7,8}$ According to the WHO, "Malocclusion is not a disease but rather a set of dental deviations which in some cases can influence quality of life," and it is highly prevalent among the Saudi population. ${ }^{10}$ The impact of malocclusion on OHRQoL enables the understanding of a patient's demand for orthodontic treatment, apart from his or her actual orthodontic treatment needs. ${ }^{11}$ Vertical discrepancy in occlusion represents the third and fifth most common orthodontic problems, which are deep overbite and open bite, respectively. ${ }^{10}$ An open bite is caused by the absence of vertical overlap of the lower incisors by the upper incisors, when the posterior teeth are in occlusion, ${ }^{12}$ while a deep bite is caused by an increased overlap of the lower incisors by the upper incisors. ${ }^{13}$

Several studies have demonstrated a relationship between malocclusion and OHRQoL. These studies assessed this relationship using the short-scale oral health impact profile tool with 14 items (OHIP-14). ${ }^{7,14-21}$

According to Chen et al and Clijmans et al, malocclusion has a negative impact on OHRQoL, mainly in the form of psychological discomfort and psychological disability; in addition, the latter researchers found that physical discomfort is also affected. ${ }^{14,15}$ Furthermore, Masood et al found that psychological discomfort is the domain that is most affected by malocclusion, followed by functional limitation. ${ }^{7}$ On the contrary, Onyeaso found that physical pain is more affected than psychological discomfort. ${ }^{16}$ The above-mentioned studies used IOTN (Index of Orthodontic Treatment Need) to classify the malocclusion groups. ${ }^{7,14-16}$ Moreover, Hassan and Amin also used the IOTN and reported a significant association between generalized mouth aching and malocclusion, selfconsciousness, tension, embarrassment, irritability, and life satisfaction. ${ }^{17}$

Rusanen et al demonstrated that patients with severe skeletal malocclusion before treatment have the poorest OHRQoL, and score the highest on OHIP-14 among the general population. ${ }^{18}$ This is in agreement with the findings of Jamilian et al, who found the OHIP scores to be lower in subjects who completed orthodontic treatment, as compared to those who did not undergo orthodontic treatment. ${ }^{19}$
Previous studies have classified malocclusion according to Angle's classification. Zheng et al found the physiological disability domain to be the most impacted in class I and III of malocclusion, while psychological discomfort and physical disability were impacted more in class II. Thus, it can be said that different malocclusion classes affect OHRQoL in varying ways. ${ }^{20}$ This contradicts the findings of Silva et al, which reported no relationship between OHRQoL and malocclusion by Angle's Classification, but found an impact of malocclusion on OHRQoL when the dental aesthetic index (DAI) was used. ${ }^{21}$

From the previous studies, it is of a prime importance to understand how the different types of malocclusion can affect patient's OHRQoL including discrepancies in the vertical dimension. Though vertical discrepancy in occlusion is highly prevalent in Jeddah, Saudi Arabia, previous studies have not evaluated its impact on OHRQoL among the Saudi population; therefore, the aim of this study, is to investigate the impact of vertical discrepancy in occlusion on the OHRQoL and assess how its severity can impact orthodontic young-adult patients who attended a screening clinic at the King Abdulaziz University in Jeddah.

It was hypothesized that vertical discrepancy in occlusion has an impact on patient's quality of life, and that impact is greater in patients with increased severity of malocclusion.

\section{Methodology}

This cross-sectional study involved young-adult participants with vertical discrepancy in occlusion, including both open and deep bites. A consecutive sample was collected from all eligible patients who attended the orthodontic screening clinic at King Abdulaziz University Dental Hospital between (November/2017) and (April/ 2018). All subjects were within the age range of 12-25 years. The ethical research committee at King Abdulaziz University approved the research under ethical approval number 058-05-17.

\section{Inclusion Criteria}

1. Patients having full permanent dentition.

2. Age: $12-25$ years.

3. Clear signs of vertical discrepancy in occlusion based on clinical examination.

\section{Exclusion Criteria}

1. Mixed dentition (since OHIP-14 questionnaire is developed for adults only). 
2. Chronic medical condition.

3. Patients who had previous orthodontic treatment.

4. Patients with mental disability.

5. Patients with genetic diseases or syndromes.

6. Patients with decay or periodontal problem.

7. Patients with dento-facial deformities like cleft lip and palate or other congenital deformities.

8. Patients with TMJ disorders and arthritis.

(This was to prevent possible confounding effects of these conditions on the participants'quality of life).

The oral health impact profile is a 49-item questionnaire that was developed in 1994 by Slade for measuring the social impact of oral disorders on people's lives and health. In 1997, a shorter, 14-item version of this questionnaire was developed. Both instruments measure the following seven domains: functional limitation, physical pain, psychological discomfort, physical disability, psychological disability, social disability, and handicap. ${ }^{22,23}$

Table I Demographic Characteristics of the Study Sample ( $N=109)$

\begin{tabular}{|l|l|}
\hline Variable & N (\%) \\
\hline Age in years (mean \pm SD) & $19.40 \pm 4.38$ \\
\hline $\begin{array}{l}\text { Gender } \\
\text { Male }\end{array}$ & $58(53.2)$ \\
Female & $51(46.8)$ \\
\hline Nationality & \\
Saudi & $93(85.3)$ \\
Non Saudi & $16(14.7)$ \\
Single & $109(100)$ \\
\hline Occupation & \\
Student & $29(4.6)$ \\
Employed Full Time & $93(85.3)$ \\
Unemployed & $11(10.1)$ \\
\hline Education & \\
Below High School & $29(26.6)$ \\
High School & $36(33.0)$ \\
Bachelors & $44(40.4)$ \\
\hline Income in SR & \\
Less than 5000 & $53(48.6)$ \\
$5000-10.000$ & $32(29.4)$ \\
More than I0.000 & $24(22.0)$ \\
\hline Feeling a need for ortho treatment & $108(99.1)$ \\
\hline Reason for seeking ortho treatment & $22(20.2)$ \\
Self-motivation & $3(2.8)$ \\
Parent & \\
Others & \\
\hline
\end{tabular}

As approved by the research ethical committee of King Abdulaziz University Dental Hospital the informed consent was verbally obtained from the participants, or from the legal guardians of participants aged below 18 years, to participate in the research after a brief explanation of the research. After obtaining verbal consent, the participants were asked to complete the Arabic version of the OHIP-14 questionnaire. $^{24}$ Thereafter, a clinical examination was conducted and the severity of malocclusion was divided as follows for open bite: 1-2 mm was considered mild, 2-4 $\mathrm{mm}$ was moderate, and $>4$ was severe. As for deep bite, more than $30 \%$ overlap was considered deep bite and classified as follows: $30-40 \%$ mild, $40-70 \%$ moderate, and $>70 \%$ was considered severe.

\section{Statistical Analysis}

Each item of the OHIP-14 questionnaire was dichotomized responses of "occasionally," "fairly often," and "very often" represented the presence of an impact on OHRQoL. Similarly, responses of "never" and "hardly

Table 2 Frequency and Percentage of Vertical Discrepancy and Presence of Impact in OHIP-I4 Daily Activity

\begin{tabular}{|c|c|c|c|}
\hline OHIP-I4 Daily Activity & $\begin{array}{l}\text { Deep } \\
\text { Bite } \\
\mathrm{N}=69\end{array}$ & $\begin{array}{l}\text { Open } \\
\text { Bite } \\
\mathbf{N}=40\end{array}$ & p-value \\
\hline $\begin{array}{l}\text { QI-Had problems } \\
\text { pronouncing words }\end{array}$ & $23(33.3)$ & $21(52.5)$ & $0.049 *$ \\
\hline $\begin{array}{l}\text { Q2-Felt that the sense of } \\
\text { taste worsened }\end{array}$ & $10(14.5)$ & $8(20.0)$ & 0.455 \\
\hline Q3-Had pain in the mouth & $26(37.7)$ & $25(62.5)$ & $0.012^{*}$ \\
\hline $\begin{array}{l}\text { Q4-Found it uncomfortable } \\
\text { to eat any food }\end{array}$ & $22(31.9)$ & $23(57.5)$ & $0.009 *$ \\
\hline Q5-Had been self-conscious & $36(52.2)$ & $31(77.5)$ & $0.009 *$ \\
\hline Q6-Felt tense & $35(50.7)$ & $22(55.0)$ & 0.667 \\
\hline Q7-Had an unsatisfactory diet & $13(18.8)$ & $13(32.5)$ & 0.107 \\
\hline Q8-Had to interrupt meals & II (I5.9) & $9(22.5)$ & 0.394 \\
\hline Q9-Found it difficult to relax & $20(29.0)$ & $16(40.0)$ & 0.239 \\
\hline $\begin{array}{l}\text { Q10-Had been a bit } \\
\text { embarrassed }\end{array}$ & $30(43.5)$ & $30(75.0)$ & $0.001 *$ \\
\hline $\begin{array}{l}\text { QII-Had been irritable with } \\
\text { other people }\end{array}$ & I5 (2I.7) & $14(35.0)$ & 0.131 \\
\hline $\begin{array}{l}\text { Q12-Had difficulty doing } \\
\text { usual jobs }\end{array}$ & $10(14.5)$ & $7(17.5)$ & 0.677 \\
\hline $\begin{array}{l}\text { Q13-Felt that life in general } \\
\text { was less satisfactory }\end{array}$ & $27(39.1)$ & $18(45.0)$ & 0.549 \\
\hline $\begin{array}{l}\text { Q14-Had been totally unable } \\
\text { to function }\end{array}$ & $7(10.1)$ & $7(17.5)$ & 0.269 \\
\hline
\end{tabular}

Note: ${ }^{*} p$-value $<0.05$

Abbreviation: OHIP-I4, oral health impact profile tool with 14 items. 
ever" denoted the absence of impact on OHRQoL. Chisquare tests or Fisher's exact tests were used as necessary. A P-value $<0.05$ denotes statistical significance. Statistical analysis was conducted using SAS software (Version 9.3; SAS Institute Inc, Cary, NC, USA).

Based on the percentages observed for selfconsciousness (Q5) in both groups, the current study used a posthoc power analysis and utilized $90 \%$ power to detect a true difference of $40 \%$ between the two groups.

\section{Results}

A total of 109 participants completed the questionnaire. Table 1 displays the demographic characteristics of the participants. The mean age of the participants was 19 years, and $58 \%$ of them were male. The majority of the participants were Saudis, and most of them $(85.3 \%)$ were full-time employed. In terms of the educational level, $40 \%$ had bachelor's degrees. Majority of the studied population $(48.6 \%)$ had an income of less than 5000 SR. Most of the participants (99.1\%) felt they needed orthodontic treatment, and regarding the reason why they sought treatment, $77.1 \%$ were self-motivated, followed by $20.2 \%$ who were encouraged by their parents to seek treatment.
Table 2 shows the frequency and percentage of impact in the OHIP-14 daily activity based on the type of vertical discrepancy. Several daily activities were significantly affected by the presence of vertical discrepancy in occlusion. The highest impact was embarrassment ( $p=0.001)$, followed by being self-conscious about their appearance, and discomfort while eating $(p=0.009)$; these are followed by toothache $(p=0.012)$ and speech problems $(p=0.049)$. This impact was significantly higher in participants with open bites.

Table 3 shows how changes in the severity of vertical discrepancy can affect the OHIP-14 score. There was no significant difference found in the impact with changing severity.

Table 4 shows that female patients are significantly more affected by embarrassment $(p=0.005)$, irritated by other people $(p=0.036)$, and experienced discomfort while eating ( $p=0.048)$. On the other hand, males were more self-conscious $(p=0.018)$, and had generalized mouth aching $(p=0.047)$.

\section{Discussion}

It is significantly important in clinical practice to assess patients' oral health status along with their needs, and

Table 3 Frequency and Percentage of the Impact of Deep or Open Bite Based on Degree of Severity

\begin{tabular}{|c|c|c|c|c|c|c|c|c|}
\hline \multirow[t]{2}{*}{ OHIP-I4 Daily Activity } & \multicolumn{3}{|c|}{ Deep Bite } & \multirow[t]{2}{*}{ p-value } & \multicolumn{3}{|c|}{ Open Bite } & \multirow[t]{2}{*}{ p-value } \\
\hline & $\begin{array}{l}\text { Mild } \\
\mathrm{N}=9\end{array}$ & $\begin{array}{l}\text { Moderate } \\
\mathrm{N}=\mathbf{2 8}\end{array}$ & $\begin{array}{l}\text { Severe } \\
\mathbf{N}=32\end{array}$ & & $\begin{array}{l}\text { Mild } \\
N=14\end{array}$ & $\begin{array}{l}\text { Moderate } \\
\mathrm{N}=18\end{array}$ & $\begin{array}{l}\text { Severe } \\
\mathbf{N}=\mathbf{8}\end{array}$ & \\
\hline QI-Had problems pronouncing words & $4(44.4)$ & $9(32.1)$ & $10(31.3)$ & 0.748 & $10(71.4)$ & 7 (38.9) & $4(50.0)$ & 0.159 \\
\hline $\begin{array}{l}\text { Q2-Felt that the sense of taste } \\
\text { worsened }\end{array}$ & $2(22.2)$ & $3(10.7)$ & $5(15.6)$ & 0.674 & $3(21.4)$ & $5(27.8)$ & $0(0.0)$ & 0.355 \\
\hline Q3-Had painful aching in the mouth & $4(44.4)$ & $10(35.7)$ & $12(37.5)$ & 0.895 & $10(71.4)$ & $12(66.7)$ & $3(37.5)$ & 0.254 \\
\hline $\begin{array}{l}\text { Q4-Found it uncomfortable to eat any } \\
\text { food }\end{array}$ & $4(44.4)$ & $8(28.6)$ & $10(31.3)$ & 0.670 & $7(50.0)$ & $13(72.2)$ & $3(37.5)$ & 0.216 \\
\hline Q5-Had been self-conscious & $4(44.4)$ & $13(46.4)$ & $19(59.4)$ & 0.565 & $12(85.7)$ & 14 (77.8) & $5(62.5)$ & 0.481 \\
\hline Q6-Felt tense & $5(55.5)$ & II (39.3) & $19(59.4)$ & 0.315 & $6(42.9)$ & II (6I.I) & $5(62.5)$ & 0.645 \\
\hline Q7-Had an unsatisfactory diet & $3(33.3)$ & $3(10.7)$ & $7(21.9)$ & 0.267 & $4(28.6)$ & $7(38.9)$ & $2(25.0)$ & 0.747 \\
\hline Q8-Had to interrupt meals & $3(33.3)$ & $3(10.7)$ & $5(15.6)$ & 0.281 & $3(21.4)$ & $5(27.8)$ & I (I2.5) & 0.886 \\
\hline Q9-Found it difficult to relax & $4(44.4)$ & $7(25.0)$ & $9(28.1)$ & 0.529 & $4(28.6)$ & $9(50.0)$ & $3(37.5)$ & 0.491 \\
\hline Q10-Had been a bit embarrassed & $4(44.4)$ & II (39.3) & $15(46.9)$ & 0.891 & II (78.6) & $13(72.2)$ & $6(75.0)$ & 0.919 \\
\hline $\begin{array}{l}\text { QII-Had been irritable with other } \\
\text { people }\end{array}$ & $I(I I . I)$ & $8(28.6)$ & $6(18.8)$ & 0.464 & $5(35.7)$ & $7(38.9)$ & $2(25.0)$ & 0.910 \\
\hline QI2-Had difficulty doing usual jobs & $I(I I . I)$ & $5(I 7.9)$ & $4(12.5)$ & 0.891 & $2(14.3)$ & $4(22.2)$ & $\mathrm{I}(12.5)$ & 0.873 \\
\hline $\begin{array}{l}\text { Q13-Felt that life in general was less } \\
\text { satisfactory }\end{array}$ & $4(44.4)$ & $13(46.4)$ & $10(31.3)$ & 0.457 & $6(42.9)$ & $9(50.0)$ & $3(37.5)$ & 0.845 \\
\hline $\begin{array}{l}\text { Q14-Had been totally unable to } \\
\text { function }\end{array}$ & $0(0.0)$ & $3(10.7)$ & $4(12.5)$ & 0.751 & I (7.I) & $4(22.2)$ & $2(25.0)$ & 0.492 \\
\hline
\end{tabular}

Abbreviation: OHIP-I4, oral health impact profile tool with 14 items. 
Table 4 Frequency and Percentage of Impact by Gender in OHIP-I4 Daily Activity

\begin{tabular}{|c|c|c|c|c|c|c|}
\hline \multirow[t]{2}{*}{ OHIP-I4 Daily Activity } & \multicolumn{3}{|l|}{ Males } & \multicolumn{3}{|l|}{ Females } \\
\hline & $\begin{array}{l}\text { Open Bite } \\
N=19\end{array}$ & $\begin{array}{l}\text { Deep Bite } \\
N=39\end{array}$ & $p$-value & $\begin{array}{l}\text { Open Bite } \\
N=21\end{array}$ & $\begin{array}{l}\text { Deep Bite } \\
N=30\end{array}$ & $p$-value \\
\hline QI-Had problems pronouncing words & $10(52.6)$ & $14(35.9)$ & 0.225 & II (52.4) & $9(30.0)$ & 0.107 \\
\hline Q2-Felt that the sense of taste worsened & $2(10.5)$ & $7(17.9)$ & 0.703 & $6(28.6)$ & $3(10.0)$ & 0.136 \\
\hline Q3-Had painful aching in the mouth & II (57.9) & $12(30.8)$ & $0.047^{*}$ & $14(66.7)$ & $14(46.7)$ & 0.253 \\
\hline Q4-Found it uncomfortable to eat any food & $9(47.4)$ & II (28.2) & 0.239 & $14(66.7)$ & II (36.7) & $0.048^{*}$ \\
\hline Q5-Had been self-conscious & $15(78.9)$ & $18(46.2)$ & $0.018^{*}$ & $16(76.2)$ & $18(60.0)$ & 0.227 \\
\hline Q6-Felt tense & $9(47.4)$ & $17(43.6)$ & 0.786 & $13(61.9)$ & $18(60.0)$ & 0.891 \\
\hline Q7-Had an unsatisfactory diet & $6(31.6)$ & $6(15.4)$ & 0.153 & $7(33.3)$ & $7(23.3)$ & 0.431 \\
\hline Q8-Had to interrupt meals & $3(15.8)$ & $5(12.8)$ & 0.758 & $6(28.6)$ & $6(20.0)$ & 0.518 \\
\hline Q9-Found it difficult to relax & $7(36.8)$ & 7 (I7.9) & 0.189 & $9(42.9)$ & $13(43.3)$ & 0.973 \\
\hline Q10-Had been a bit embarrassed & $14(73.7)$ & $19(48.7)$ & 0.094 & $16(76.2)$ & II (36.7) & $0.005^{*}$ \\
\hline QII-Had been irritable with other people & $4(21.1)$ & $9(23.1)$ & 0.862 & $10(47.6)$ & $6(20.0)$ & $0.036 *$ \\
\hline QI2-Had difficulty doing usual jobs & $2(10.5)$ & $6(15.4)$ & 0.615 & $5(23.8)$ & $4(13.3)$ & 0.334 \\
\hline $\begin{array}{l}\text { QI3-Felt that life in general was less } \\
\text { satisfactory }\end{array}$ & $7(36.8)$ & $16(41.0)$ & 0.760 & II (52.4) & II (36.7) & 0.265 \\
\hline QI4-Had been totally unable to function & $3(15.8)$ & $5(12.8)$ & 0.758 & $4(19.0)$ & $2(6.7)$ & 0.214 \\
\hline
\end{tabular}

Note: $*_{p}$-value $<0.05$

Abbreviation: OHIP-I4, oral health impact profile tool with 14 items.

how it impacts their quality of life. ${ }^{17,25}$ As such, this study evaluates the impact of vertical discrepancy in occlusion on the OHRQoL to better understand how different types of malocclusion affect quality of life, using the validated Arabic version of OHIP-14 among young adults seeking orthodontic treatment at the King Abdulaziz University Dental Hospital in Jeddah. The Arabic OHIP-14 has been used in previous studies to assess the quality of life with different malocclusions. ${ }^{17,24,26}$

In our study we found a statistically significant association between anterior vertical discrepancy in occlusion and embarrassment $(\mathrm{p}=0.001)$, followed by being selfconscious about their appearance, discomfort while eating $(p=0.009)$, generalized mouth aching $(p=0.012)$, and speech problems $(p=0.049)$. These findings are in line with those of previous studies that evaluated OHRQoL in different malocclusions. ${ }^{7,14-18}$

When assessing the impact of the change in the severity of vertical discrepancy in occlusion, there was no significant relation. Thus, malocclusion impacts patients' OHRQoL regardless of its severity.

Most articles in the literature report that more females seek dental treatment than males. During the time frame of this study, however, the number of young men and women who sought orthodontic treatment at our university clinics were nearly equivalent. ${ }^{5,7,14-18}$
Regarding gender, we found that females are significantly more embarrassed by the condition of their teeth and tend to be more irritable with other people than males. ${ }^{18,21}$ This may possibly mean that women are reacting to the social significance of a desire for aesthetics, as opposed to their male counterparts, who focused more on the orthodontic treatment. ${ }^{7,16,21,25}$

The study's cross-sectional design can be viewed as a limitation of this research, though longitudinal tracking would not change the outcomes fundamentally, as occlusion is built up by the age run analyzed in this study.

\section{Conclusion}

Vertical discrepancy in occlusion demonstrates a negative impact on OHRQoL and its domains. This has been highlighted in the domains of psychological disability, psychological discomfort, physical pain, and functional limitation. Considering the gender variables, females were significantly more affected in the psychological and social disability domains, while males were more affected in the psychological discomfort domain; however, both genders were significantly affected in the domain of physical pain.

\section{Disclosure}

The authors declare that they have no conflicts of interest. 


\section{References}

1. Oral health in America: A report of the Surgeon General. Rockville, Maryland, US Department of Health and Human Services, National Institute of Dental and Craniofacial Research. National Institute of Health; 2000:7 (NIH publication 00-4713).

2. Gift HC, Atchison KA, Dayton CM. Conceptualizing oral health and oral health related quality of life. Soc Sci Med. 1997;44(5):601-608. doi:10.1016/S0277-9536(96)00211-0

3. De Oliveira CM, Sheiham A. Orthodontic treatment and its impact on oral health-related quality of life in Brazilian adolescents. $J$ Orthod. 2004;31(1):20-27. doi:10.1179/146531204225011364

4. Al SM. Oral health-related quality of life: a broader perspective. East Mediterr Health J. 2006;12(6):894-901.

5. Feu D, de Oliveira BH, de Oliveira Almeida MA, Kiyak HA, Miguel JA. Oral health related quality of life and orthodontic treatment seeking. Am J Orthod Dentofacial Orthop. 2010;138:152-159. doi:10.1016/j.ajodo.2008.09.033

6. Mühlberg S, Jäger J, Krohn-Grimberghe B, et al. Oral health-related quality of life depending on oral health in patients with rheumatoid arthritis. Clin Oral Investig. 2017;21:2661-2670. doi:10.1007/s007 84-017-2068-4

7. Masood Y, Masood M, Nadiah N, et al. Impact of malocclusion on oral health related quality of life in young people. Health Qual Life Outcomes. 2013;11:1-6.

8. Abdul Majid ZA, Abidia RF. Effects of malocclusion on oral health related quality of life (OHRQoL): a critical review. Eur Sci J. 2015;11:386-400.

9. Chen M, Andersen RM, Barmes DE, Leclerq M-H, Lyttle SC. Comparing Oral Health Systems. A Second International Collaborative Study. Geneva: World health organization; 1997.

10. Hassan AH. Orthodontic treatment needs in the western region of Saudi Arabia: a research report. Head Face Med. 2006;6:1-6.

11. Masood M, Masood Y, Saub R, Newton JT. Need of minimal important difference for oral health-related. $J$ Public Health Dent. 2012;74:13-20. doi:10.1111/j.1752-7325.2012.00374.x

12. Mitchell L. An Introduction to Orthodontics. OUP Oxford; 2013.

13. Baratam S, Cvvr S. Annals and essences of dentistry deep overbite a review (Deep bite, deep overbite, excessive overbite). Ann Essences Dent. 2009;1(1):8-25.

14. Chen M, Feng Z, Liu X, Li Z, Cai B, Wang D. Impact of malocclusion on oral health - related quality of life in young adults. Angle Orthod. 2015;85(6):986-991. doi:10.2319/101714-743.1
15. Clijmans M, Lemiere J, Fieuws S, Willems G. Original article: impact of self-esteem and personality traits on the association between orthodontic treatment need and oral health-related quality of life in adults seeking orthodontic treatment. Eur J Orthod. 2015;37 (6):643-650. doi:10.1093/ejo/cju092

16. Onyeaso CO. Orthodontic treatment complexity and need with associated oral health-related quality of life in nigerian adolescents. Oral Health Prev Dent. 2009;7(3):235-241.

17. Hassan HA, Amin HS. Association of orthodontic treatment needs and oral health-related quality of life in young adults. Am J Orthod Dentofacial Orthop. 2010;137:42-47. doi:10.1016/j.ajodo.2008.02. 024

18. Rusanen J, Lahti S, Tolvanen M, Pirttiniemi P. Quality of life in patients with severe malocclusion before treatment. Eur J Orthod. 2010;32:43-48. doi:10.1093/ejo/cjp065

19. Jamilian A, Kiaee B, Sanayei S, Khosravi S, Perillo L. Orthodontic treatment of malocclusion and its impact on oral health-related quality of life. Open Dent J. 2016;10(2713):236-241. doi:10.2174/187 4210601610010236

20. Zheng D, Wang X, Su Y, et al. Assessing changes in quality of life using the Oral Health Impact Profile (OHIP) in patients with different classifications of malocclusion during comprehensive orthodontic treatment. BMC Oral Health. 2015;15;1-8.

21. Silva G, Thomaz F, Freitas L, et al. Impact of Malocclusion on the Quality of Life of Brazilian Adolescents: a Population-Based Study. PLoS One. 2016;11(9):1-13. doi:10.1371/journal.pone.0162715

22. Slade GD, Spencer AJ. Development and evaluation of the Oral Health Impact Profile. Community Dent Health. 1994;11(1):3-11.

23. Slade GD. Derivation and validation of a short-form oral health impact profile. Community Dent Oral Epidemiol. 1997;25:284-290. doi:10.1111/j.1600-0528.1997.tb00941.x

24. Al-jundi MA, Szentpetery A, John MT. An Arabic version of the Oral Health Impact Profile: translation and psychometric properties. Int Dent J. 2007;57:84-92. doi:10.1111/j.1875-595X.2007.tb00443.x

25. Tsakos G, Gherunpong S, Sheiham A. Can oral health-related quality of life measures substitute for normative needs assessments in 11 to 12-year-old children? J Public Health Dent. 2006;66:263-268. doi:10.1111/j.1752-7325.2006.tb04079.x

26. Hassan AH, Hobani NM, Almokri SM, et al. Effect of anterior crowding or spacing on oral health-related quality of life: a cross-sectional study. Patient Prefer Adherence. 2018;12:461-465. doi:10.2147/PPA.S149081
Patient Preference and Adherence

\section{Publish your work in this journal}

Patient Preference and Adherence is an international, peer-reviewed, open access journal that focuses on the growing importance of patient preference and adherence throughout the therapeutic continuum. Patient satisfaction, acceptability, quality of life, compliance, persistence and their role in developing new therapeutic modalities and compounds to optimize clinical outcomes for existing disease states are major areas of interest for the journal. This journal has been accepted for indexing on PubMed Central. The manuscript management system is completely online and includes a very quick and fair peer-review system, which is all easy to use. Visit http:// www.dovepress.com/testimonials.php to read real quotes from published authors. 